\title{
Rheumatoid Arthritis Real-world Management Over 20 Years
}
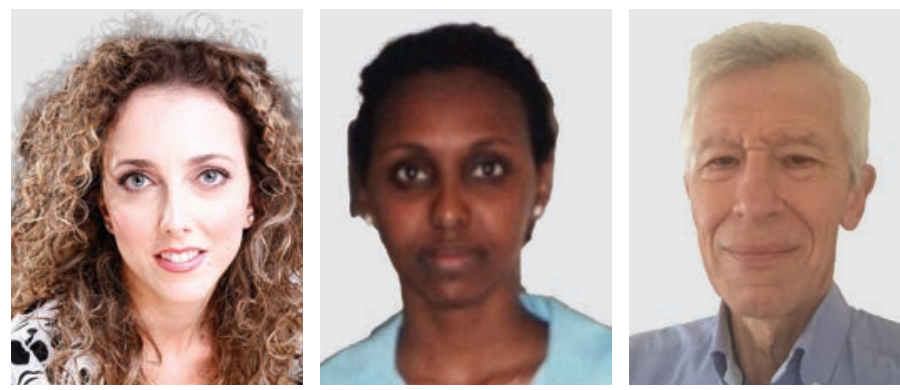

\section{Elena Nikiphorou $^{1}$ (D), Fowzia $\operatorname{Ibrahim}^{1}{ }^{(\mathbb{D})}$, and David L. Scott ${ }^{1}$ (D)}

Clinical trials show which treatments improve rheumatoid arthritis (RA), whereas observational studies show how patients are managed in routine practice. Prospective cohort studies give the most detailed information about what happens to patients, but being a part of a prospective study influences patient management because patients are no longer routine cases. In contrast, large healthcare databases provide the broadest overviews of real-world management. Such studies have different limitations: The information they contain is relatively restricted, and there are often some uncertainties about the diagnosis of RA. Hanly and Lethbridge ${ }^{1}$ have analyzed a large healthcare database, the Nova Scotia Medical Services Insurance program, which held information on over 8000 elderly patients with RA followed over a period of 20 years. During this time, prescribing of both conventional disease-modifying antirheumatic drugs (cDMARD) and biologics increased. In contrast, prescribing of nonsteroidal antiinflammatory drugs (NSAID) declined. However, there were 2 concerns. First, many patients never saw a rheumatologist. Second, steroid prescribing remained relatively constant and, in many patients, steroids were prescribed by physicians who were not rheumatologists.

National and international RA guidelines capture the essence of good management ${ }^{2}$. They promote promptly treating active RA with cDMARD, and using biologics and the newer targeted synthetic DMARD in patients with incomplete responses. The value of NSAID are considered minimal. Recommendations on steroid prescribing are nuanced. Patients with active RA and flares

${ }^{1}$ E. Nikiphorou, MD (Res), Adjunct Senior Lecturer and Consultant Rheumatologist, F. Ibrahim, PhD, Research Fellow in Medical Statistics, D.L. Scott, MD, Emeritus Professor of Rheumatology, Centre for Rheumatic Diseases, Department of Inflammation Biology, School of Immunology and Microbial Sciences, Faculty of Life Sciences and Medicine, King's College London, UK.

Address correspondence to Dr. D.L. Scott, Centre for Rheumatic Diseases, Department of Inflammation Biology, School of Immunology and Microbial Sciences, Faculty of Life Sciences and Medicine, King's College London, Cutcombe Road, London SE5 9RJ, UK.

Email:d.scott1@nhs.net,david.l.scott@kcl.ac.uk. are considered to benefit from short-term steroids, though the potential risks from steroids mean they should be tapered as soon as possible and long-term use avoided. Finally, guidelines consider rheumatologists to have key roles in managing RA and recommend that patients with RA be seen by rheumatologists.

Over the last 20 years, multiple trials and patient registers have created a strong evidence base for increasing the use of cDMARD and biologics. As a consequence, their prescribing has gradually increased across a range of diverse clinical settings. In Nova Scotia, use of cDMARD doubled over 2 decades from 1997. By 2017, two-thirds of patients were receiving them. A comparable English study of over 35,000 patients with RA in the Clinical Practice Research Datalink ${ }^{3}$ also showed substantial increases in cDMARD prescribing. At the same time, there was considerable unexplained regional variations in prescribing DMARD. In 1995, cDMARD were prescribed to $19-49 \%$ of patients in different regions; this percentage increased to $45-74 \%$ by 2010 . cDMARD prescribing in an English specialist center showed similar increases, though even in this setting a substantial minority of patients did not receive them ${ }^{4}$. In Nova Scotia, biologic prescribing increased from none to one-fifth of patients over 20 years. Comparable observational studies from North America ${ }^{5}$ and Europe ${ }^{4,6}$ showed similar or even greater increases.

Although these increases in real-world DMARD and biologic prescribing are reassuring, several key issues remain unresolved. First, despite the emphasis on prompt treatment, observational studies in early RA show that many patients do not start these drugs in the first year of disease ${ }^{7}$. Treatment is particularly delayed in seronegative patients ${ }^{8}$. Second, there are divergent views on combining 2 or more cDMARD; some experts recommend CDMARD combinations, whereas others are unconvinced of their value. One consequence of these differences in opinion is the possibility that biologics may often be started before patients have received sufficient cDMARD9. Third, there are uncertainties about the extent to which guidelines about DMARD prescribing have major influences on routine practice. Harrold, et a ${ }^{10}$ evalu-

See Corticosteroid use in RA, page 977 
ated the effect of the 2008 American College of Rheumatology guidelines for prescribing DMARD in over 20,000 patients with RA seen more than 100,000 times before and after the guidelines were published. In these patients, the guidelines had little effect on the treatments many of them were prescribed. However, internationally the situation is complex: A multinational survey of care in early RA showed that despite substantial variations in referrals, early assessment pathways linked to guidelines have important effects in northern Europe ${ }^{11}$. The reasons underlying these national variations in applying guidelines are unknown.

With steroid prescribing, the situation is complicated. In Nova Scotia, the level of steroid prescribing had remained unchanged over 2 decades. Approximately one-third of patients received at least 1 steroid prescription each year with prednisone, the steroid given most often. Family physicians were responsible for most of the stable prescribing. Given the risks of taking longterm steroids, particularly prednisone, there were concerns that the quantities of steroids used, particularly long-term steroids, were excessive. Set against these concerns are beliefs in the benefits of steroid treatment to control disease in early RA. An English national audit of initial management given to over 7000 early RA patients seen in 2014-2015 showed that over three-quarters of these patients received steroids ${ }^{12}$. Early steroid therapy was associated with good clinical responses. Far fewer of these patients received combinations of cDMARD. The audit also highlighted that the management of individual patients often deviated from guideline recommendations, with marked variability in treatment decisions between units. The situation is comparable in the United States. Wallace, et al $^{13}$ analyzed treatments received by over 9000 RA patients under 65 years in the first year of their RA recorded in a national administrative database. Over $70 \%$ received at least 1 steroid prescription and about one-third received over 3 months of steroid treatment at average doses of $10 \mathrm{mg}$ of prednisone daily. This American dataset also showed considerable individual variations in prescribing between rheumatologists without any obvious clinical basis, which is similar to the findings in the multinational survey ${ }^{11}$. There are undoubtedly circumstances in which low-dose steroids benefit RA patients when they have ongoing active disease, and the balance of evidence from trials supports using steroids in some patients ${ }^{14}$.

Variations between rheumatologists in prescribing steroids was assessed in more detail by George, et a ${ }^{15}$ using 2 cohorts of RA patients created from Medicare data collected from 2006 to 2015. After analyzing over 1 million annual observations in more than 350,000 patients, they categorized rheumatologists' preference for prescribing steroids, which were highly variable. Frequent prescribers used steroids about one-third more often. Subsequent analysis of over 150,000 patients treated with stable DMARD therapy showed that rheumatologists who were high steroid users prescribed steroids daily to one-fifth of their patients, whereas low steroid users prescribed them to one-tenth of patients. Such variability in steroid prescribing implies that a substantial proportion of patients have received too many steroids for too long.

The other important issue highlighted in Nova Scotia was that many patients with RA never saw a rheumatologist ${ }^{1}$. It is challenging putting this finding into context because observational studies using large databases apply different methods to identify RA patients. Observational studies organized by rheumatologists like the English Early RA Network study select only patients who have received specialist $\mathrm{care}^{16}$. In these studies, the diagnosis of RA is not in doubt, but their design means that they ignore patients never seen by rheumatologists. Algorithms to identify RA patients in large databases such as the General Practice Research Database and its successor, the Clinical Practice Research Datalink, are complex and variable ${ }^{17}$. Using algorithms that include receiving DMARD to categorize RA patients has several strengths ${ }^{18}$, but such approaches are likely to exclude patients who have not seen rheumatologists. Such considerations make it difficult to know how many patients have never seen rheumatologists. An early study from 2000 by MacLean, et al ${ }^{19}$, which assessed the quality of care received by RA patients, used a similar diagnostic algorithm to that used in the Nova Scotia patients. MacLean and colleagues also found that only about half the periods of care they assessed involved input from rheumatologists. It seems likely that the pattern of specialist involvement in RA has not changed substantially over the last 2 decades, with many patients not seen by rheumatologists.

Several factors influence rheumatology referral for RA. Local factors like specialist numbers, geography and transport, and referral pathways can all be important. There may be fewer opportunities to see a rheumatologist in rural areas than in cities because access may be more challenging. The patients with RA in Nova Scotia were all elderly and this may also have influenced the specialist care they received. Elderly patients with RA often have multiple disorders ${ }^{20}$. Such patients are frequently less concerned about their RA than their other disorders ${ }^{21}$. They may prefer their care being managed by 1 generalist rather than seeing different specialists for each of their different disorders. Managing multimorbidity, which remains an unresolved challenge in elderly people 22 , may have been a factor in many Nova Scotia patients not receiving rheumatology care. Such multimorbidity is an increasing problem in RA. Observational studies show an increasing comorbidity burden on first disease presentation in RA, calling for the need of treatment strategies in early RA that place greater emphasis on the presence of comorbid disease $^{23}$. High use of steroids has also been linked to multimorbidity in $\mathrm{RA}^{24}$, which may help explain why nonspecialists prescribed steroids in Nova Scotia.

Delivering high-quality clinical care involves minimizing the differences between what ought to happen, based on the evidence for treatment, and what actually happens in real life as shown in observational studies. While the increases in DMARD and biologic prescribing over recent years in many different clinical settings is reassuring, there is still evidence of variability in the levels of prescribing, implying that care may often be suboptimal. The situation with steroid prescribing, though more complex, also suggests considerable variability in prescribing, with many patients potentially receiving too many steroids. We consider that there is a strong case for developing approaches to reduce the high levels of variation, though the best way to achieve this goal in the present environment is uncertain. One potentially 
important additional factor at present is that steroids are considered to potentially increase the risk of coronavirus disease 2019 (COVID-19) infections. In England, patients taking long-term steroids for rheumatic diseases were advised to "shield" during the coronavirus pandemic because of these concerns ${ }^{25}$. Traditionally, audits have been considered as drivers for minimizing unwarranted variations in care. However, the COVID-19 pandemic led to the National Audit of Early Arthritis in England being suspended. Given the way the pandemic has changed rheumatology clinics, many of which are using remote consultations, there may be opportunities to harness the growing use of digital recording of clinical data. This area appears ripe for new initiatives. Finally, RA guidelines have been traditionally led by rheumatologists, with minimal involvement of other medical specialists. While this approach is understandable, it is unlikely to change the involvement of generalists and other medical specialists in caring for patients with RA. There is a case to rebalance the groups developing guidelines by involving more specialists outside of rheumatology.

\section{REFERENCES}

1. Hanly JG, Lethbridge L. Disease modifying anti-rheumatic drugs, biologics and corticosteroid use in older patients with rheumatoid arthritis over 20 years. J Rheumatol 2021;48:977-84.

2. Mian A, Ibrahim F, Scott DL. A systematic review of guidelines for managing rheumatoid arthritis. BMC Rheumatol 2019;3:42.

3. Edwards CJ, Campbell J, van Staa T, Arden NK. Regional and temporal variation in the treatment of rheumatoid arthritis across the UK: a descriptive register-based cohort study. BMJ Open 2012;2:e01603.

4. Mian AN, Ibrahim F, Scott IC, Bahadur S, Filkova M, Pollard L, et al. Changing clinical patterns in rheumatoid arthritis management over two decades: sequential observational studies. BMC Musculoskelet Disord 2016;17:44.

5. Kavanaugh A, Singh R, Karki C, Etzel CJ, Kremer JM, Greenberg $\mathrm{JD}$, et al. Disease activity and biologic use in patients with psoriatic arthritis or rheumatoid arthritis. Clin Rheumatol 2018;37:2275-80.

6. Gossen N, Jacob L, Kostev K. Second-line therapy with biological drugs in rheumatoid arthritis patients in German rheumatologist practices: a retrospective database analysis. Rheumatol Int 2016;36:1113-8.

7. Steffen A, Holstiege J, Klimke K, Akmatov MK, Bätzing J. Patterns of the initiation of disease-modifying antirheumatic drugs in incident rheumatoid arthritis: a German perspective based on nationwide ambulatory drug prescription data. Rheumatol Int 2018;38: 2111-20.

8. Pratt AG, Lendrem D, Hargreaves B, Aslam O, Galloway JB, Isaacs JD. Components of treatment delay in rheumatoid arthritis differ according to autoantibody status: validation of a single-centre observation using national audit data. Rheumatology 2016; 55:1843-8.

9. O'Dell JR, Cohen SB, Thorne JC, Kremer J. Treatment of rheumatoid arthritis in the USA: premature use of tumor necrosis factor inhibition and underutilization of concomitant methotrexate. Open Access Rheumatol 2018;10:97-101.

10. Harrold LR, Harrington JT, Curtis JR, Furst DE, Bentley MJ, Shan $\mathrm{Y}$, et al. Prescribing practices in a US cohort of rheumatoid arthritis patients before and after publication of the American College of Rheumatology treatment recommendations. Arthritis Rheum 2012;64:630-8.

11. Nikiphorou E, Galloway J, van Riel P, Yazici Y, Haugeberg G, Ostor A, et al; QUEST-RA. The spectrum of early rheumatoid arthritis practice across the globe: results from a multinational cross sectional survey. Clin Exp Rheumatol 2017;35:477-83.

12. Yates M, MacGregor AJ, Ledingham J, Norton S, Bechman K, Dennison EM, et al. Variation and implications of treatment decisions in early rheumatoid arthritis: results from a nationwide cohort study. Rheumatology 2020;59:2035-42.

13. Wallace BI, Lin P, Kamdar N, Noureldin M, Hayward R, Fox DA, et al. Patterns of glucocorticoid prescribing and provider-level variation in a commercially insured incident rheumatoid arthritis population: retrospective cohort study. Semin Arthritis Rheum 2020;50:228-36.

14. Kavanaugh A, Wells AF. Benefits and risks of low-dose glucocorticoid treatment in the patient with rheumatoid arthritis. Rheumatology 2014;53:1742-51.

15. George MD, Baker JF, Wallace B, Chen L, Wu Q, Xie F, et al. Variability in glucocorticoid prescribing for rheumatoid arthritis and the influence of provider preference on long-term use. Arthritis Care Res 2020 Jul 23 (E-pub ahead of print).

16. Carpenter L, Norton S, Nikiphorou E, Jayakumar K, McWilliams $\mathrm{DF}$, Rennie KL, et al. Reductions in radiographic progression in early rheumatoid arthritis over twenty-five years: changing contribution from rheumatoid factor in two multicenter UK inception cohorts. Arthritis Care Res 2017;69:1809-17.

17. Thomas SL, Edwards CJ, Smeeth L, Cooper C, Hall AJ. How accurate are diagnoses for rheumatoid arthritis and juvenile idiopathic arthritis in the general practice research database? Arthritis Rheum 2008;59:1314-21.

18. Muller S, Hider SL, Raza K, Stack RJ, Hayward RA, Mallen CD. An algorithm to identify rheumatoid arthritis in primary care: a Clinical Practice Research Datalink study. BMJ Open 2015;5:e009309.

19. MacLean CH, Louie R, Leake B, McCaffrey DF, Paulus HE, Brook $\mathrm{RH}$, et al. Quality of care for patients with rheumatoid arthritis. JAMA 2000;284:984-92.

20. van Onna M, Boonen A. The challenging interplay between rheumatoid arthritis, ageing and comorbidities. BMC Musculoskelet Disord 2016;17:184.

21. van Onna M, Öztürk B, Starmans M, Peeters R, Boonen A. Disease and management beliefs of elderly patients with rheumatoid arthritis and comorbidity: a qualitative study. Clin Rheumatol 2018;37:2367-72.

22. Duffield SJ, Ellis BM, Goodson N, Walker-Bone K, Conaghan PG, Margham T, et al. The contribution of musculoskeletal disorders in multimorbidity: Implications for practice and policy. Best Pract Res Clin Rheumatol 2017;31:129-44.

23. Nikiphorou E, Norton S, Carpenter L, Dixey J, Walsh DA, Kiely P, et al; Early Rheumatoid Arthritis Study and the Early Rheumatoid Arthritis Network Cohorts. Secular changes in clinical features at presentation of rheumatoid arthritis: increase in comorbidity but improved inflammatory states. Arthritis Care Res 2017;69:21-7.

24. Nikiphorou E, Fragoulis GE. Inflammation, obesity and rheumatic disease: common mechanistic links. A narrative review. Ther Adv Musculoskelet Dis 2018;10:157-67.

25. British Society for Rheumatology. COVID-19 guidance. [Internet. Accessed September 4, 2020.] Available from: www.rheumatology. org.uk/practice-quality/covid-19-guidance 